\title{
PERFIL DOS GASTOS PÚBLICOS VERSUS PERFIL ECONÔMICO-SOCIAL DOS MUNICÍPIOS PAULISTAS
}

\section{PROFILE OF PUBLIC EXPENDITURE VERSUS SOCIAL-ECONOMIC PROFILE OF MUNICIPALITIES IN THE STATE OF SÃO PAULO}

\author{
PATRÍCIA SIQUEIRA VARELA \\ Doutora em Controladoria e Contabilidade pela \\ Universidade de São Paulo \\ São Paulo/SP, Brasil \\ E-mail: psvarela@usp.br
}

\author{
GILBERTO DE ANDRADE MARTINS \\ Professor Titular do Departamento de Contabilidade e Atuária \\ da Faculdade de Economia, Administração e Contabilidade da \\ Universidade de São Paulo \\ São Paulo/SP, Brasil \\ E-mail: martins@usp.br
}

\author{
LUIZ JOÃO CORRAR \\ Professor Doutor da Faculdade de Economia, Administração \\ e Contabilidade da Universidade de São Paulo \\ São Paulo/SP, Brasil \\ E-mail: ljcorrar@usp.br
}

\section{Resumo}

0 presente artigo teve como objetivo agrupar municípios paulistas quanto ao perfil dos gastos públicos per capita por função e descrever as relações entre os agrupamentos obtidos e os grupos definidos pelo Índice Paulista de Responsabilidade Social (IPRS). 0 interesse surgiu da constatação de existência de grupos de municípios definidos pelo IPRS com o mesmo nível de riqueza e diferentes resultados quanto aos indicadores sociais e vice-versa. Com base nas características do processo produtivo de bens públicos, adotou-se como premissa subjacente às análises que o montante e qualidade do gasto público estariam, de certa forma, caracterizando tal situação. Os resultados obtidos a partir das técnicas de análise de conglomerados e de correspondência indicaram que todos os grupos de municípios, de certo modo, apresentaram gastos elevados nas funções-meio e o montante de recursos aplicados nas funções sociais apresentou associação positiva com os indicadores socioeconômicos dos municípios.

Palavras-chave: gastos públicos; perfil econômico-social; municípios.

\begin{abstract}
This article aimed at both grouping municipalities in the State of São Paulo regarding profile of public expenditure per capita according to function, and describing the relationships among these groups and those obtained through the definition of the Paulista Index of Social Responsibility (IPRS). The interest in the subject stemmed from the awareness that groups of municipalities ranked by the IPRS have the same level of wealth but bear different results regarding social indices and vice-versa. The premise underlying the analyses - that the amount and quality of public expenditure would, in a way, characterize such situation - was adopted based on the characteristics of the production process of public goods. The results reached with clusters and correspondence analyses techniques showed that, to a certain degree, all municipalities presented high expenses as regards means functions; also the amount of revenue invested in social functions associated positively with the social economic indices of municipalities.
\end{abstract}

Key words: public expenditure, social-economic profile, municipalities. 


\section{INTRODUÇÃO}

Nas últimas décadas, a administração pública brasileira tem vivido um intenso processo de transformação sob influência da redemocratização do país e da reforma do Estado, em que a descentralização tem sido uma estratégia comum dos dois movimentos, favorecendo a transferência de poder, recursos e atribuições para os governos locais.

0 município é o ente federativo que mais tem sofrido os impactos desse processo de mudança da administração pública brasileira, por estar sendo considerado depositário das reais possibilidades de intervenção do Estado e, ao mesmo tempo, por estar despreparado para assumir as novas responsabilidades a ele direcionadas.

Uma das principais modificações em curso, nesse novo contexto, é a transformação do foco de interesse da administração pública de processos para resultados, o que favorece a ênfase nos aspectos de planejamento e controle, visando à utilização ótima dos recursos públicos. Tal fato, aliado ao maior acesso a fontes de informações pela população, representa condições essenciais ao exercício da participação popular e do controle social.

A expansão das bases de dados e o uso de indicadores sociais têm sido incorporados aos instrumentos que subsidiam os gestores públicos no processo decisório. Como lembra Jannuzzi (2001, p.11), os indicadores sociais “[...] passaram a integrar o vocabulário corrente dos agentes políticos responsáveis, em última instância, pela definição das prioridades das políticas sociais e alocação dos recursos públicos”.

Uma das iniciativas mais conhecidas quanto ao uso de indicadores sociais é a da Organização das Nações Unidas - ONU que, na década de 90, criou o Índice de Desenvolvimento Humano - IDH, apresentando uma inovação ao introduzir, em sua concepção, as variáveis longevidade e educação, além da renda, para comparar o grau de desenvolvimento dos países. Outras experiências surgiram a partir do IDH, sendo o caso do Índice Paulista de Responsabilidade Social - IPRS, construído pela Fundação Sistema Estadual de Análise de Dados (SEADE), órgão do governo do estado de São Paulo, com o objetivo de classificar os municípios paulistas segundo a qualidade de vida dos seus habitantes.

A análise da realidade dos governos locais do estado de São Paulo, sob a ótica do IPRS, indica a existência de grupos de municípios com combinações diferentes de riqueza e indicadores de longevidade e escolaridade, observando-se situações em que municípios com o mesmo nível de riqueza não apresentam os mesmos resultados quanto aos indicadores sociais e vice-versa (FUNDAÇÃO SEADE, 2005, p.10).

Uma das possíveis explicações é a não semelhança quanto à distribuição dos gastos públicos por funções, ou seja, entre as funções saúde e educação e cultura (principais ações desenvolvidas pela gestão local), outras funções sociais e aquelas não ligadas diretamente à prestação de serviços à sociedade - funções-meio.

Sendo assim, este trabalho tem como objetivo realizar um agrupamento dos municípios paulistas, de acordo com seu perfil de gastos públicos, e comparar os grupos obtidos com aqueles identificados pela Fundação SEADE com base nos indicadores de renda, longevidade e escolaridade.

A premissa subjacente ao estudo é que o montante e a qualidade dos gastos dos municípios interferem no seu desempenho em termos de geração de riqueza, situação de saúde e educação da população - aspectos abrangidos pelo IPRS. Por qualidade, entende-se a distribuição dos recursos entre as funções-fim (serviços prestados) e funções-meio.

0 agrupamento dos municípios quanto às variáveis relativas aos gastos públicos por funções foi feito por meio da técnica estatística multivariada análise de conglomerados. Já 
para a análise descritiva das relações entre os grupos de municípios de acordo com perfil dos gastos públicos e dos grupos de municípios definidos pelo IPRS, realizou-se uma análise de correspondência, técnica estatística multivariada que permite que o pesquisador visualize, em um mapa perceptual, as proximidades/distâncias entre as categorias das variáveis, indicando relações existentes entre elas (HAIR JR et. al., 2005, p.441).

Este estudo torna-se relevante no sentido de possibilitar uma avaliação conjunta da qualidade dos gastos públicos e da situação econômico-social dos municípios paulistas, com inovação quanto à abordagem de comparação dos dados.

\section{PRODUÇÃO DE BENS PÚBLICOS E USO DE INDICADORES NO PROCESSO ORÇAMENTÁRIO}

Para se avaliar o desempenho e promover a accountability no setor público, é preciso conhecer seus objetivos, a forma de funcionamento, como são sistematizadas as informações em planos e orçamentos e as medidas e parâmetros de desempenho (VARELA, 2008, p.37). O que, por sua vez, pressupõe saber quais são as características dos bens públicos e como eles são produzidos pelas organizações do setor público.

A intervenção do setor público na produção de bens torna-se necessária quando o consumo é não-rival e/ou quando não se pode aplicar o princípio da exclusão. 0 consumo não-rival significa que o consumo dos bens por uma determinada pessoa não implica em uma diminuição dos benefícios disponíveis para o resto da coletividade, ou seja, os mesmos benefícios encontram-se ao alcance de todos e não há interferência mútua entre os indivíduos quando eles usufruem desses benefícios. A exclusão ocorre quando o consumo por um indivíduo implica em que ele tenha pago o preço do referido bem, enquanto outro, que não pagou por este bem, está excluído do consumo (MUSGRAVE; MUSGRAVE, 1980, p.42). A não aplicação do princípio da exclusão acontece por ser inviável ou muito dispendiosa ou pela característica de consumo não-rival do bem, não se justificando a exclusão uma vez que o custo marginal do consumo por mais uma pessoa é zero. A inabilidade de exclusão do consumo é devida aos altos custos de transação, conforme definido por Arrow (1970, p. 10), ou seja, custos de fazer o sistema econômico funcionar.

O consumo não-rival e a não-exclusão são situações de falha do sistema de mercado e tais idéias estão presentes nas definições de bens públicos encontradas na teoria econômica, como em Samuelson (1954, 1955), Tiebout (1956), Musgrave e Musgrave (1980), Stiglitz (1988).

Claramente, ser ou não rival é a característica fundamental que difere bens públicos de bens privados conforme definição de Samuelson (1954). A mesma linha de raciocínio é encontrada em Musgrave e Musgrave (1980, p. 44), os autores reconhecem que pode haver falhas no sistema de mercado pelo fato de o bem apresentar apenas a característica de não-exclusão, mas os bens são considerados públicos quando a nãorivalidade está presente. Para estes últimos autores, a natureza não-rival do consumo de bens públicos modifica as condições de utilização eficiente de recursos no sentido de Pareto. Stiglitz (1988, p. 128) conceitua bens públicos puros como aqueles para os quais não existe rivalidade no consumo e a exclusão é impossível.

$\mathrm{Na}$ análise de bens privados, um dos principais pressupostos é que o consumo de uma pessoa não afeta a utilidade das outras pessoas, portanto, a otimização do consumo individual é suficiente para alcançar uma espécie de ótimo social. Já quando se trata de bens públicos, as utilidades das pessoas estão inexoravelmente ligadas, uma vez que todas têm que consumir a mesma quantidade do bem público (VARIAN, 2006, p. 733). 
Musgrave e Musgrave (1980, p. 47) mencionam que a visão polarizada entre bens privados, cujos benefícios são completamente internalizados (rival), e bens públicos, cujos benefícios são completamente externalizados (não-rival), é válida para auxiliar a compreensão da diferença essencial entre bens públicos e privados. Todavia, não é realista, pois, na prática, existem situações mistas de várias espécies, dando origem aos chamados Bens Mistos. Nesses casos, aos benefícios internalizados pelo consumidor individual se somam os benefícios externalizados, o que é característico, por exemplo, da provisão de serviços de saúde.

A produção de bens públicos envolve a transformação de uma combinação de inputs em um conjunto de outputs (serviços prestados). De acordo com Cohen e Franco (2004, p. 77), os conceitos utilizados em avaliação de projetos sociais foram desenvolvidos pela economia e estão associados à função de produção que vincula recursos, insumos, processos e produtos.

Shah (2007, p. 11), ao tratar de transferências intergovernamentais vinculadas à obtenção de resultados, menciona que o administrador público de um governo recebedor de recursos poderia examinar os diversos elementos de um programa a fim de determinar se os resultados seriam ou não alcançados, quais sejam: (i) inputs (recursos usados para produzir outputs), incluindo inputs intermediários; (ii) outputs (quantidade e qualidade dos bens e serviços públicos produzidos e o acesso aos mesmos); (iii) outcomes (conseqüências de médio/longo prazo para os contribuintes/consumidores da provisão dos serviços públicos ou grau de alcance dos objetivos do programa), (iv) impacto (objetivos do programa ou conseqüências de longo prazo); e alcance (pessoas beneficiadas ou prejudicadas pelo programa). Um exemplo da área de educação pode ser visualizado pela Figura 1:

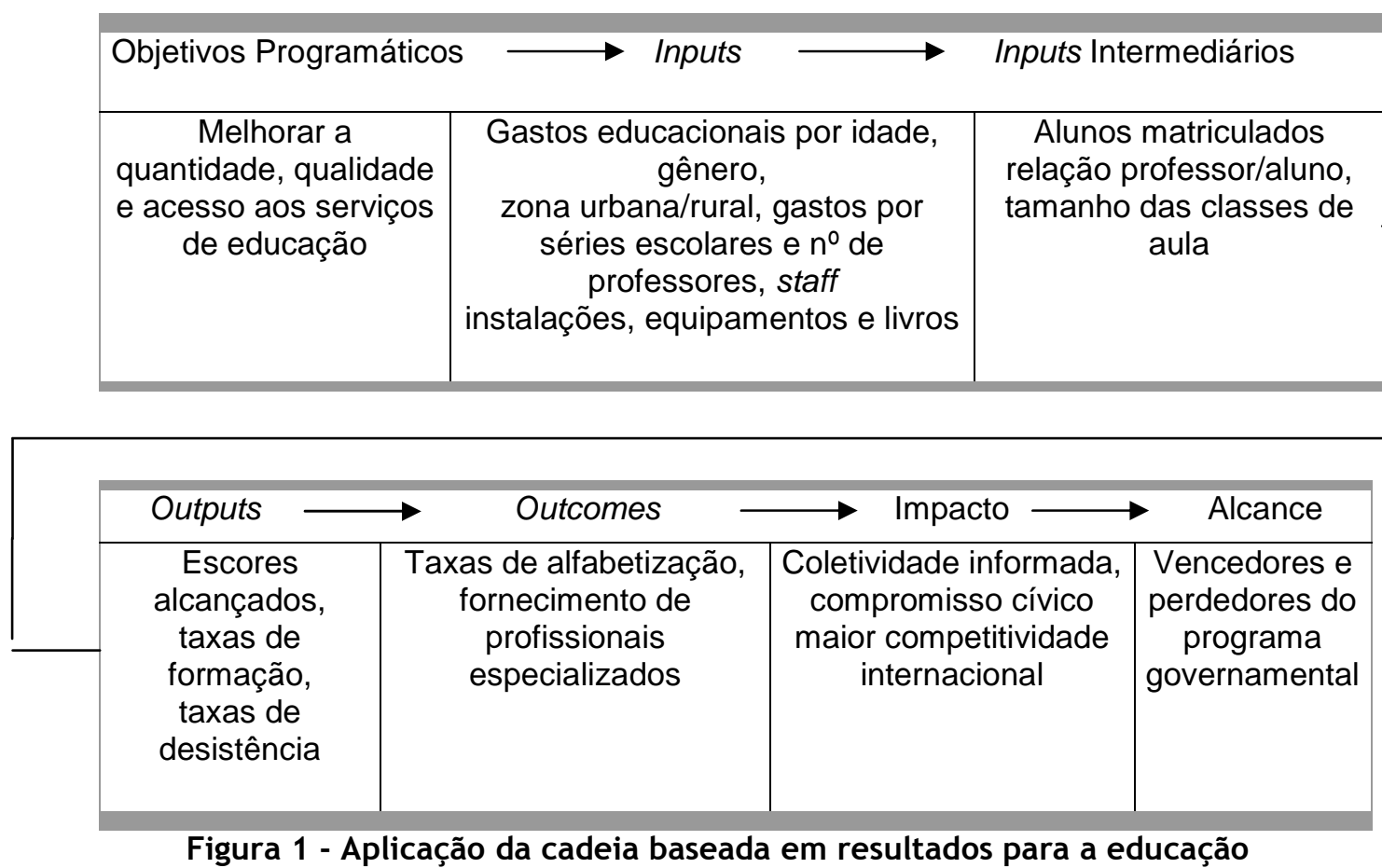

Figura 1 - Aplicação da cadeia baseada em resultados para a educação FONTE: SHAH, 2007, p. 11.

Cohen e Franco (2004, p. 93) ao tratar das saídas do processo de produção, destacam a distinção entre produtos, efeitos e impactos. Os efeitos são resultados da utilização dos produtos e o impacto, a conseqüência dos efeitos de um projeto, ou seja, o grau de consecução dos objetivos (estado desejado) em relação à população-meta. 
Pelas abordagens de Cohen e Franco (2004) e Shah (2007), é possível perceber que, no processo de provisão de bens e serviços públicos, a dificuldade em mensurar os outputs surge de forma mais aguda do que na produção de bens privados.

Bradford, Malt e Oates (1969) já haviam se preocupado com esta questão e buscaram esclarecê-la com o desenvolvimento de um modelo em que os outputs são separados entre diretos (Output-D) e de interesse final do cidadão (Output-C). Por exemplo, o produto final de um programa sentido por uma população não é o número de vacinas aplicadas, mas a redução da mortalidade infantil. Combinações diferentes de inputs (Input-I) geram vetores de bens e serviços diretamente produzidos. Os vetores de outputs finais, por sua vez, são completamente determinados pelo vetor de outputs diretos e por certas variáveis ambientais ou exógenas, por exemplo, as condições de saneamento no caso da saúde.

Os esforços recentes de modernização da administração pública, cujo foco é gestão voltada para resultados e o uso eficiente dos recursos, têm como uma de suas forças motrizes a mudança dos objetivos e da cultura do processo de planejamento e orçamento. Nesse sentido, a ênfase do controle sobre os elementos de despesa cede lugar à mensuração e avaliação da eficiência, eficácia e efetividade dos programas governamentais. Portanto, o interesse não se restringe às modificações nas condições de riqueza, longevidade e escolaridade da população, mas também como os recursos foram utilizados para alcançar tais modificações.

Os resultados dos programas relacionam-se com o grau de alcance dos objetivos traçados com base na realidade empírica que se pretendia modificar, por exemplo, diminuição do número de analfabetos. Para avaliar um programa governamental, é preciso tentar determinar até que ponto ele contribuiu para as modificações verificadas na situação econômica e social da população em um determinado período de tempo, ou seja, se existiu efetividade. Além disso, é relevante averiguar se o que foi proposto fazer foi realizado (eficácia), por exemplo, o número de alunos atendidos pela rede pública de ensino (produtos das ações de educação) e se o foi com o mínimo de recursos possíveis sem sacrificar a qualidade (eficiência).

A trajetória evolutiva do orçamento público evidencia que em cada momento histórico foi enfatizada uma de suas funções ou instrumentalidades: controle, gerência ou planejamento. 0 uso de indicadores no processo orçamentário começa a ganhar destaque quando a ênfase deixa de ser na função controle e passa para a gerência e, logo em seguida, planejamento das ações governamentais. Assim, a necessidade de informação sobre "em que" e "para que" se gastam os recursos públicos é adicionada àquela sobre "o que" o governo adquire, tornando proeminente o processo de mensuração das ações orçamentárias.

O orçamento de desempenho inaugura a necessidade de incorporar medidas físicas como uma consideração relevante na alocação dos recursos orçamentários. Neste tipo de orçamento, a ênfase é na gerência e administração e, conseqüentemente, nos custos e realizações (produtos) das atividades, ou seja, na implementação dos programas governamentais. Portanto, os tipos de indicadores a serem usados seriam os de insumo, processo, output, eficiência e eficácia.

No orçamento por programas, com orientação para o planejamento, a relevância recai na verificação dos resultados (impactos) nas condições econômicas e sociais da comunidade, o que pressupõe a determinação dos indicadores representativos dos objetivos dos programas, ou seja, os de outcomes e efetividade.

A dificuldade de estabelecer relacionamentos entre aplicação de recursos públicos e resultados dos programas sociais municipais faz parte de uma discussão mais ampla que é 
a de estabelecer relações entre indicadores de processos $\mathrm{e}$ indicadores de produtos/resultados.

No processo de avaliação das ações governamentais, existem limitações em relacionar diretamente recursos públicos usados e resultados alcançados. De acordo com Aristigueta et. al. (2001, p.262), não é possível afirmar que se o ente governamental é eficiente ou eficaz, necessariamente, haverá mudanças nas condições de saúde e bemestar da população, mas, conforme Burkhead (1971, p.186), informações sobre o desempenho (eficiência e eficácia) poderão contribuir para o julgamento de valor, em termos políticos e feito para a sociedade, sobre o alcance dos programas sociais.

Existem poucos estudos que buscam conciliar recursos orçamentários e produtos/resultados das políticas públicas. Alguns deles usam Data Envelopment Analysis (DEA), Análise Envoltória de Dados, que é uma técnica de otimização, baseada em programação linear e projetada para estabelecer uma medida de eficiência relativa entre diferentes unidades tomadoras de decisão (DMU's), podendo ser citados os seguintes trabalhos:

* A tese de doutoramento de Campello (2003) que trata da eficiência dos municípios do estado de São Paulo em duas dimensões: eficiência de exploração, relativa à capacidade de explorar as bases tributárias, e eficiência de transformação, cujo foco é como os municípios conseguem transformar os recursos que dispõe (públicos e privados) em qualidade de vida (medida pelos indicadores de longevidade e escolaridade). Os resultados indicaram que os municípios paulistas possuíam baixas eficiências de exploração e altos valores de eficiência de transformação.

- O Working paper do Banco Central da Europa de autoria de Afonso et. al. (2003), o qual apresenta um modelo operacional para computar o desempenho de 23 países industrializados da OCDE (Organização para a Cooperação e Desenvolvimento Econômico), utilizando-se a técnica de fronteira de produção não-paramétrica Full Disposal Hull (FDH), variação dos modelos clássicos de DEA;

- O artigo de Sousa et. al. (2003) que calcula a eficiência técnica de 4796 municípios brasileiros e combina outras técnicas com o intuito de eliminar outliers e possíveis erros no conjunto de dados;

* O trabalho de Borger e Kerstens (1996) que analisa a eficiência dos governos locais na Bélgica com o uso de duas técnicas não-paramétricas (FDH e DEA) e de três técnicas paramétricas;

- O artigo de Borger et. al. (1994), cujo objetivo era mensurar e explicar as variações na eficiência produtiva nos municípios da Bélgica, usando a técnica não-paramétrica FDH.

Outros trabalhos tratam especificamente de algumas funções públicas, especialmente saúde e educação, como:

* O trabalho de Gupta e Verhoeven (2001), cujo objetivo foi avaliar a eficiência da despesa governamental em educação e saúde em 37 países da África entre 1984 e 1995.

* O trabalho de Afonso e Aubyn (2004) que usa as técnicas não-paramétricas FDH e DEA para medir a eficiência em educação e saúde para uma amostra de países da OCDE (Organização para a Cooperação e Desenvolvimento Econômico);

Destaque também deve ser dado ao trabalho de Scarpin (2006) que usou análise de regressão múltipla para estimar um modelo de previsão dos valores futuros do Índice de 
Desenvolvimento Humano Municipal (IDH-M), cuja população objeto de estudo foi constituída por todos os municípios do estado do Paraná. $O$ autor conclui a pesquisa evidenciando que o IDH-M possui relação com as variáveis: IDH-M passado, distância à capital, altitude do município, nível de população rural, receita tributária, despesa com pessoal, despesa com saúde e saneamento, investimentos e gastos com indústria e comércio.

\section{3 ÍNDICE PAULISTA DE RESPONSABILIDADE SOCIAL - IPRS}

O IPRS tem como objetivo a classificação dos municípios do estado de São Paulo segundo a qualidade de vida dos seus habitantes. Para isso, foram consideradas as três dimensões abrangidas pelo IDH (renda, longevidade e escolaridade), mas utilizando-se outras variáveis mais condizentes com a realidade municipal. A idéia inicial era usar indicadores que permitissem a avaliação não somente dos resultados e esforços empreendidos pelo poder público em prol do desenvolvimento em âmbito local, mas também a mensuração do grau de participação e controle da sociedade civil sobre tais ações.

Para a obtenção deste índice, os municípios do Estado de São Paulo foram classificados em grupos com características similares de riqueza, longevidade e escolaridade por meio da análise de conglomerados (cluster analysis), grupos estes com as seguintes denominações: (1) municípios-pólo, (2) economicamente dinâmicos e de baixo desenvolvimento social, (3) saudáveis e de baixo desenvolvimento econômico, (4) de baixo desenvolvimento econômico e em transição social e (5) de baixo desenvolvimento econômico e social. As variáveis consideradas em cada uma das dimensões do IPRS e a correspondente estrutura de ponderação utilizada estão sintetizadas na Tabela 1.

Tabela 1 - Síntese das Variáveis Selecionadas e Estrutura de Pesos Adotada, segundo Dimensões do IPRS

\begin{tabular}{|c|c|c|}
\hline Dimensão do IPRS & Variáveis Selecionadas & $\begin{array}{l}\text { Contribuição para o } \\
\text { indicador sintético }\end{array}$ \\
\hline Riqueza Municipal & $\begin{array}{l}\text { Consumo residencial de energia elétrica } \\
\text { Consumo de energia elétrica na agricultura, no } \\
\text { comércio e nos serviços } \\
\text { Remuneração média dos empregados com carteira } \\
\text { assinada e do setor público } \\
\text { Valor adicionado fiscal per capita }\end{array}$ & $\begin{array}{l}44 \% \\
23 \% \\
19 \% \\
14 \%\end{array}$ \\
\hline Longevidade & $\begin{array}{l}\text { Mortalidade perinatal } \\
\text { Mortalidade infantil } \\
\text { Mortalidade de pessoas de } 15 \text { a } 39 \text { anos } \\
\text { Mortalidade de pessoas de } 60 \text { anos e mais }\end{array}$ & $\begin{array}{l}30 \% \\
30 \% \\
20 \% \\
20 \%\end{array}$ \\
\hline Escolaridade & $\begin{array}{l}\text { Percentagem de jovens de } 15 \text { a } 17 \text { anos que } \\
\text { concluíram o ensino fundamental } \\
\text { Percentagem de jovens de } 15 \text { a } 17 \text { anos com pelo } \\
\text { menos quatro anos de escolaridade } \\
\text { Percentagem de jovens de } 18 \text { a } 19 \text { anos que } \\
\text { concluíram o ensino médio } \\
\text { Percentagem de crianças de cinco e seis anos que } \\
\text { freqüentam pré-escola }\end{array}$ & $\begin{array}{l}36 \% \\
8 \% \\
36 \% \\
20 \%\end{array}$ \\
\hline
\end{tabular}

Fonte: Fundação SEADE, 2005, p.5. 
O indicador sintético de cada dimensão é o resultado da combinação das variáveis, sendo que o peso de cada uma delas na referida combinação foi obtido por meio de Análise Fatorial. Para facilitar o manuseio dos dados e a comparação de municípios, o indicador foi transformado em uma escala que varia de 0 a 100.

A fundação SEADE sintetizou os indicadores de riqueza municipal, longevidade e escolaridade em escalas categóricas, as quais expressam o "padrão geral" dos grupos criados. A síntese dos critérios adotados para a formação dos grupos de municípios pelo IPRS está descrita no Quadro 1.

Quadro 1 - Critérios de Formação dos Grupos do IPRS

\begin{tabular}{|c|c|c|}
\hline $\begin{array}{l}\text { Grupos } \\
\text { do IPRS }\end{array}$ & Critérios de Formação dos Grupos do IPRS & Descrição \\
\hline Grupo 1 & $\begin{array}{l}\text { Alta riqueza, alta longevidade e média escolaridade } \\
\text { Alta riqueza, alta longevidade e alta escolaridade } \\
\text { Alta riqueza, média longevidade e média escolaridade } \\
\text { Alta riqueza, média longevidade e alta escolaridade }\end{array}$ & $\begin{array}{l}\text { Municípios que se } \\
\text { caracterizam por um } \\
\text { nível elevado de } \\
\text { riqueza com bons } \\
\text { níveis nos indicadores } \\
\text { sociais }\end{array}$ \\
\hline Grupo 2 & $\begin{array}{l}\text { Alta riqueza, baixa longevidade e baixa escolaridade } \\
\text { Alta riqueza, baixa longevidade e média escolaridade } \\
\text { Alta riqueza, baixa longevidade e alta escolaridade } \\
\text { Alta riqueza, média longevidade e baixa escolaridade } \\
\text { Alta riqueza, alta longevidade e baixa escolaridade }\end{array}$ & $\begin{array}{l}\text { Municípios que, } \\
\text { embora com níveis de } \\
\text { riqueza elevados, não } \\
\text { são capazes de atingir } \\
\text { bons indicadores } \\
\text { sociais }\end{array}$ \\
\hline Grupo 3 & $\begin{array}{l}\text { Baixa riqueza, alta longevidade e média escolaridade } \\
\text { Baixa riqueza, alta longevidade e alta escolaridade } \\
\text { Baixa riqueza, média longevidade e média escolaridade } \\
\text { Baixa riqueza, média longevidade e alta escolaridade }\end{array}$ & $\begin{array}{l}\text { Municípios com nível } \\
\text { de riqueza baixo, mas } \\
\text { com bons indicadores } \\
\text { sociais }\end{array}$ \\
\hline Grupo 4 & $\begin{array}{l}\text { Baixa riqueza, baixa longevidade e média escolaridade } \\
\text { Baixa riqueza, baixa longevidade e alta escolaridade } \\
\text { Baixa riqueza, média longevidade e baixa escolaridade } \\
\text { Baixa riqueza, alta longevidade e baixa escolaridade }\end{array}$ & $\begin{array}{c}\text { Municípios que } \\
\text { apresentam baixos } \\
\text { níveis de riqueza e } \\
\text { níveis intermediários de } \\
\text { longevidade e/ou } \\
\text { escolaridade } \\
\end{array}$ \\
\hline Grupo 5 & Baixa riqueza, baixa longevidade e baixa escolaridade & $\begin{array}{l}\text { Este grupo concentra } \\
\text { os municípios mais } \\
\text { desfavorecidos do } \\
\text { Estado, tanto em } \\
\text { riqueza como nos } \\
\text { indicadores sociais }\end{array}$ \\
\hline
\end{tabular}

Fonte: Fundação SEADE, 2005, p.10.

Pelo Quadro 1, é possível perceber as diferentes combinações entre níveis de riqueza municipal e de indicadores sociais. 0 grupo 3 chama a atenção por possuir baixa riqueza municipal e, mesmo assim, conseguir alcançar bons indicadores sociais, diferentemente do contexto econômico do grupo 1 , o qual possui alta riqueza. Por outro lado, observa-se que o grupo 2 possui alta riqueza e não consegue bons indicadores sociais e os grupos 4 e 5 têm baixa riqueza e baixos indicadores de longevidade e escolaridade. Portanto, cabe a indagação se o montante e a qualidade dos gastos públicos relacionam-se com o perfil econômico-social dos grupos de municípios.

É importante frisar que um dos principais objetivos do IPRS é avaliar os gestores públicos municipais em diferentes momentos. Contudo, a avaliação da gestão municipal deve passar, necessariamente, pela forma de alocação dos recursos públicos disponíveis em cada governo local. 


\section{GASTOS PÚBLICOS CLASSIFICADOS POR FUNÇÃO}

O melhor entendimento da abrangência e da orientação prevalecente em um orçamento público é alcançado com a análise das classificações das receitas e, principalmente, das despesas públicas. Isso porque “[...] a classificação orçamentária é um meio de observação e dá à informação sôbre operações governamentais a forma e estrutura essenciais à análise e inferência." (BURKHEAD, 1971, p.145).

Burkhead $(1971,149)$ considera a classificação funcional ou por funções como a “classificação para os cidadãos” porque gera informações gerais sobre as operações do governo, podendo ser apresentadas em uma espécie de "orçamento resumido". O objetivo principal da Classificação Funcional é mostrar, de maneira sintética, "em que" são gastos os recursos públicos: educação, saúde, assistência social, direitos de cidadania, administração etc.

Giacomoni (2000, p.98) destaca a capacidade da classificação de “[...] fornecer as bases para a apresentação de dados e estatísticas sobre os gastos públicos nos principais segmentos em que atuam as organizações do Estado."

A estrutura da antiga classificação funcional-programática estabelecida pela Portaria $n^{\circ}$ 9/74 foi substituída pela Portaria $n^{\circ} 42 / 99$ com aplicação aos orçamentos da União, Estados e Distrito Federal para o exercício financeiro de 2000 e dos municípios para o exercício financeiro de 2002. A Portaria $n^{\circ} 42 / 99$ separa a classificação funcional da estrutura programática.

O critério funcional de classificação da despesa possui duas categorias: função e subfunção. A função é entendida como "o maior nível de agregação das diversas áreas de despesa que competem ao setor público" e as subfunções "uma partição da função, visando agregar determinado subconjunto de despesa do setor público." (art. $1^{\circ}$, §§ $1^{\circ}$ e $3^{\circ}$ da Portaria $\left.n^{\circ} 42 / 99\right)$.

A Portaria $n^{\circ}$ 42/99 define, em seu anexo, 28 funções e 109 subfunções aplicáveis a todos os entes da federação, possibilitando, dessa forma, a consolidação das contas públicas e a comparação entre diferentes entidades.

Uma das inovações da classificação foi a criação da Função 28 - Encargos Especiais que "[...] engloba as despesas em relação às quais não se possa associar um bem ou serviço a ser gerado no processo produtivo corrente, tais como: dívidas, ressarcimentos, indenizações e outras afins, representando, portanto, uma agregação neutra". (art. $1^{\circ}$, § $2^{\circ}$ da Portaria $n^{\circ} 42 / 99$ ).

\section{ASPECTOS METODOLÓGICOS}

Para o alcance dos objetivos deste estudo, realizou-se uma pesquisa quantitativa e descritiva de todos os municípios do estado de São Paulo e foi estabelecido um método de coleta e análise dos dados com características apresentadas nas seções a seguir.

\subsection{POPULAÇÃO}

A população objeto de estudo corresponde à capital e a todos os municípios do interior do estado de São Paulo. 


\subsection{BASES E COLETA DE DADOS}

Foram coletados dados referentes aos Grupos de Municípios do IPRS e aos Gastos Públicos por Funções. Os dados do IPRS foram coletados no site da Fundação SEADE (2009) e são referentes ao ano de 2006. Os dados referentes às despesas liquidadas classificadas por função do exercício de 2006 tiveram como fonte o site do Sistema do Tesouro Nacional (2009). Os dados são relativos aos 645 municípios paulistas.

Para realização da análise, as despesas por função foram separadas conforme indicado a seguir:

* Saúde.

- Educação e Cultura.

* Assistência e Previdência.

* Outras Funções Sociais: Trabalho; Direitos de Cidadania; Habitação; Urbanismo; Gestão Ambiental; Ciência e Tecnologia; Agricultura; Organização Agrária; Indústria, comércio e serviço; Comunicações; Energia; Transporte; Desporto e lazer; Saneamento; e Segurança Pública.

- Legislativa.

- Administração.

* Outras Funções Meio: Judiciária; Essencial à Justiça; Defesa Nacional; Relações Exteriores.

- Encargos Especiais.

As despesas foram, ainda, divididas pela população de cada município com o intuito de diminuir as discrepâncias entre os valores apresentados, portanto, trabalhou-se com as despesas liquidadas por função per capita.

\subsection{MÉTODOS DE ANÁLISE DOS DADOS}

Com o intuito de agrupar os municípios paulistas quanto ao Perfil dos gastos públicos e descrever as relações entre os agrupamentos obtidos e os grupos definidos pelo IPRS, foram aplicadas duas técnicas estatísticas multivariadas: análise de conglomerados e análise de correspondência.

A análise de conglomerados é a técnica adequada para agrupar objetos, neste caso municípios, com base nas características que eles possuem, de modo que "[...] os agrupamentos resultantes de objetos devem então exibir elevada homogeneidade interna (dentro dos agrupamentos) e elevada heterogeneidade externa (entre agrupamentos)." (HAIR JR et. al., 2005, p.384).

A formação dos grupos é realizada segundo determinado critério de distância entre os respectivos vetores de dados e de acordo com um método de agregação especificado.

Há dois procedimentos de agrupamento: o hierárquico e o não hierárquico. 0 método hierárquico envolve a construção de uma estrutura de hierarquia do tipo árvore e fornece uma série de soluções correspondentes a diferentes números de conglomerados. Uma forma de definir a quantidade de agrupamentos na solução é a análise da medida de similaridade ou distância entre os conglomerados. Já no método não hierárquico, o processo de agrupamento é mais dinâmico e interativo e produz apenas uma solução para o número de conglomerados requisitados, que deve ser especificado pelo analista (HAIR JR et. al., 2005, p.398-403). 
O método não hierárquico $K$-Means pode ser usado para o agrupamento de grandes conjuntos de observações, cujo objetivo é a minimização da variância interna aos grupos e maximização da variância entre os grupos.

A análise de correspondência, por sua vez, estabelece a associação entre categorias de características descritivas ou atributos específicos de objetos ou casos (HAIR JR et. al., 2005, p.441). Por meio da análise de correspondência é possível perceber as relações entre diferentes características dos objetos mostradas em um mapa bi ou tridimensional em que as categorias mais semelhantes são colocadas próximas umas das outras.

De acordo com Hoffman e Franke (1986: 213), a análise de correspondência objetiva o agrupamento das categorias (de linhas e colunas) de respostas de duas ou mais variáveis. A partir da decomposição de uma matriz de distâncias qui-quadrado, o algoritmo da análise de correspondência produz uma série de matrizes que são aplicadas às linhas e colunas de uma tabela de contingência para que sejam produzidas distâncias entre os pontos, base para geração de um gráfico em dimensões reduzidas.

Sendo assim, os municípios categorizados em cinco grupos conforme o IPRS e os clusters formados com base no perfil de gastos públicos per capita por função foram plotados em um mapa bidimensional com o objetivo de indicar, por exemplo, se a categoria de municípios com maior desenvolvimento econômico e social estava próximo dos categorizados com maior montante e melhor qualidade dos gastos públicos.

Para a correta aplicação da técnica de análise de conglomerados, é preciso realizar alguns procedimentos iniciais: análise dos dados missing, padronização das variáveis e tratamento dos outliers.

\subsubsection{Tratamento dos missing (dados perdidos)}

Em relação aos dados perdidos, o pesquisador deve se concentrar nos motivos que os geraram (HAIR JR. et al., 2005, p.56). Oito municípios foram excluídos da análise pela não existência de dados sobre despesas no site do STN. Além disso, alguns municípios apresentaram valor zero para algumas funções que sabidamente não poderia acontecer, por exemplo, Legislativa, nesses casos optou-se pela eliminação de mais doze municípios. Em relação aos Encargos Especiais, havia um grande número de casos com valor zero, mas como esta situação é possível mantiveram-se todos os municípios. A variável "Outras Funções Meio" foi eliminada, por se tratarem de funções que não são típicas de governos municipais e por vários casos apresentarem valor zero. Após os procedimentos adotados, 625 dos 645 municípios permaneceram no estudo.

\subsubsection{Padronização das Variáveis}

A análise de conglomerados é sensível à escala ou magnitude entre variáveis, portanto, um cuidado importante é a padronização dos valores de cada uma das variáveis sob estudo. Apesar de os gastos públicos por função serem apresentados por valores per capita, entre cada função existem diferenças quanto ao montante aplicado em cada município. Portanto, optou-se por usar o método de padronização Z-scores, o qual aplica a cada valor a subtração da média da variável e a divisão do resultado pelo desvio padrão.

\subsubsection{Tratamento dos outliers (observações atípicas)}

0 tratamento das observações atípicas foi feito sobre o total de 625 municípios. As observações atípicas podem ser classificadas em quatro classes (HAIR JR. et al., 2005, p.71): 
a) observações atípicas que ocorrem por erro na entrada de dados ou falha na codificação;

b) observações que ocorrem devido a um evento extraordinário;

c) observações extraordinárias para as quais o pesquisador não tem explicação;

d) observações que estão no intervalo usual de valores para cada variável, porém são únicas em sua combinação de valores entre as variáveis.

Neste trabalho, 54 casos foram eliminados por apresentarem valores muito discrepantes em pelo menos uma das variáveis. Para isso, utilizou-se como critério de corte + ou - 2,5 desvios padrões da média de cada uma das variáveis, separadamente.

\section{ANÁLISE DOS RESULTADOS}

\subsection{ANÁLISE DE CONGLOMERADOS}

Para atingir o objetivo de agrupar os municípios conforme o perfil dos gastos públicos foram utilizadas as seguintes variáveis padronizadas:

- Despesas Liquidadas com Administração per capita;

- Despesas Liquidadas com Função Legislativa per capita;

- Despesas Liquidadas com Assistência e Previdência per capita;

- Despesas Liquidadas com Saúde per capita;

- Despesas Liquidadas com Educação e Cultura per capita;

- Despesas Liquidadas com Outras Funções Sociais per capita;

- Despesas Liquidadas com Encargos Especiais per capita;

Inicialmente, foi aplicada a técnica de Análise de Conglomerados, procedimento hierárquico, com a finalidade de determinar o número de agrupamentos na solução. Utilizou-se o método Ward linkage com a medida de distância quadrática Euclideana. A medida de distância entre os conglomerados indicava a escolha de cinco clusters ou menos na solução. Como o IPRS divide os municípios em cinco grupos e o teste One-Way ANOVA indicava que as médias eram diferentes para todas as variáveis, adotou-se, inicialmente, a solução com cinco agrupamentos. Contudo, tal solução não estava adequada à realização do teste qui-quadrado, pré-requisito para a análise de correspondência. Por isso, optou-se pela formação de quatro grupos.

Usando-se o número de clusters sugeridos pelo procedimento hierárquico, foi processado o método K-Means Cluster para obtenção da melhor solução que minimizasse a variância dentro dos grupos e maximizasse a variância entre os grupos. Novamente, foi aplicado o teste One-Way ANOVA que indicou a diferença de médias de cada uma das variáveis entre os grupos. A Tabela 2 apresenta os valores das variáveis calculados para os centróides dos quatro conglomerados. 


\begin{tabular}{|l|r|r|r|r|}
\hline \multirow{2}{*}{\multicolumn{1}{c|}{$\begin{array}{c}\text { Variáveis } \\
\text { Padronizadas }\end{array}$}} & \multicolumn{4}{c|}{ Cluster } \\
\cline { 2 - 5 } & $\mathbf{1}$ & $\mathbf{2}$ & \multicolumn{1}{c|}{$\mathbf{3}$} & \multicolumn{1}{c|}{$\mathbf{4}$} \\
\hline Saúde & $-0,64212$ & 1,11464 & $-0,21828$ & 0,31405 \\
\hline Educação e Cultura & $-0,62711$ & 0,95156 & 0,13690 & 0,05929 \\
\hline Assistência e Previdência & $-0,46132$ & 0,76757 & $-0,30410$ & 0,39787 \\
\hline Outras Funções Sociais & $-0,53126$ & 0,78926 & $-0,27472$ & 0,31401 \\
\hline Administração & $-0,54640$ & 1,05537 & $-0,13853$ & $-0,02706$ \\
\hline Legislativa & $-0,60449$ & 1,09571 & $-0,24518$ & 0,23120 \\
\hline Encargos Especiais & $-0,02682$ & $-0,16429$ & $-0,65670$ & 0,48576 \\
\hline
\end{tabular}

Os valores encontrados das variáveis padronizadas para os centróides refletem a ordem de grandeza dos valores encontrados nos respectivos conglomerados.

De maneira geral, os grupos 2 e 4 foram os que aplicaram maiores valores per capita nas funções governamentais. 0 grupo 2 foi o que aplicou maiores valores per capita tanto nas funções sociais quanto nas funções meio. Os maiores gastos foram nas funções Saúde, Legislativa, Administração e Educação e Cultura, nesta ordem. Este grupo se posiciona em segundo lugar quanto aos menores gastos per capita com Encargos Especiais.

No grupo 4, as maiores aplicações de recursos foram em Encargos Especiais, Assistência e Previdência, Saúde e Outras Funções Sociais. As funções Educação e Cultura apresentaram, em conjunto, valores per capita menores do que todas as outras funções, com exceção da Administração e, entre os grupos, se posicionaram em segundo lugar quanto aos menores valores per capita aplicados em tal função.

Em oposição aos grupos 2 e 4, tem-se o grupo 1 que aplicou os menores valores per capita em todas as funções, indicando a menor disponibilidade de recursos públicos para implementar políticas econômicas e sociais. Além disso, os valores per capita aplicados nas funções meio têm uma representatividade parecida com aqueles investidos nas funções sociais. Este grupo apresentou a segunda maior aplicação de recursos em Encargos Especiais.

Em uma situação intermediária, encontra-se o grupo 3, mas com algumas peculiaridades. A prioridade do gasto público está nas funções, Educação e Cultura, Administração, Saúde e Legislativa, nesta ordem. Este grupo apresenta a segunda maior aplicação per capita em Educação e Cultura e os menores valores per capita em Encargos Especiais.

Ao se observar o número de casos por conglomerado na Tabela 3, percebe-se uma escala piramidal, na qual poucos casos são municípios com os maiores valores de gastos públicos per capita por função. As quantidades de casos com valores intermediários (grupos 3 e 4) e baixos valores (grupo 1) quase que se equivalem e representam a maioria.

Tabela 3 - Número de Casos por Conglomerado

\begin{tabular}{|c|c|}
\hline Conglomerado & Número de casos \\
\hline 2 & 62 \\
\hline 4 & 103 \\
\hline 3 & 145 \\
\hline 1 & 261 \\
\hline
\end{tabular}




\subsection{ANÁLISE DE CORRESPONDÊNCIA}

Antes de processar a análise de correspondência, a realização do teste quiquadrado é recomendada para esclarecer se a distribuição das variáveis por categoria é aleatória ou se há um padrão determinado por interdependência entre as variáveis. Conforme Maroco (2003, p.86), o teste qui-quadrado serve para testar se a frequiência com que os elementos da amostra se repartem pelas classes de uma variável categorizada é ou não idêntica.

Foi feito o teste qui-quadrado, cuja hipótese nula de independência entre as variáveis "Conglomerados por Perfil dos Gastos Públicos" e "Grupos do IPRS" foi rejeitada a um nível de significância de 0,05 , indicando a possibilidade de realizar a análise de correspondência. Utilizou-se, para isso, a medida de distância euclidiana e o método de normalização simétrica para solução em duas dimensões.

A proporção da Inércia indica a quantidade de informação restituída por cada dimensão (a variância retida em cada dimensão). É possível perceber que a dimensão 1 apresenta $83,8 \%$ da inércia e a dimensão 2 apresenta 14,3\%, conforme Tabela 4.

\section{Tabela 4 - Inércia de Cada Dimensão do Mapa Bidimensional}

\begin{tabular}{|l|r|r|}
\hline \multirow{2}{*}{ Dimensão } & \multicolumn{2}{|c|}{ Proporção da Inércia } \\
\cline { 2 - 3 } & \multicolumn{1}{|c|}{ Individual } & Cumulativo \\
\hline 1 & 0,838 & 0,838 \\
\hline 2 & 0,143 & 0,980 \\
\hline 3 & 0,020 & 1,000 \\
\hline Total & 1,000 & 1,000 \\
\hline
\end{tabular}

Pelo mapa perceptual (Figura 2) é possível perceber as relações entre os conglomerados de municípios formados a partir do perfil dos gastos públicos per capita por função e os grupos definidos pelo IPRS.

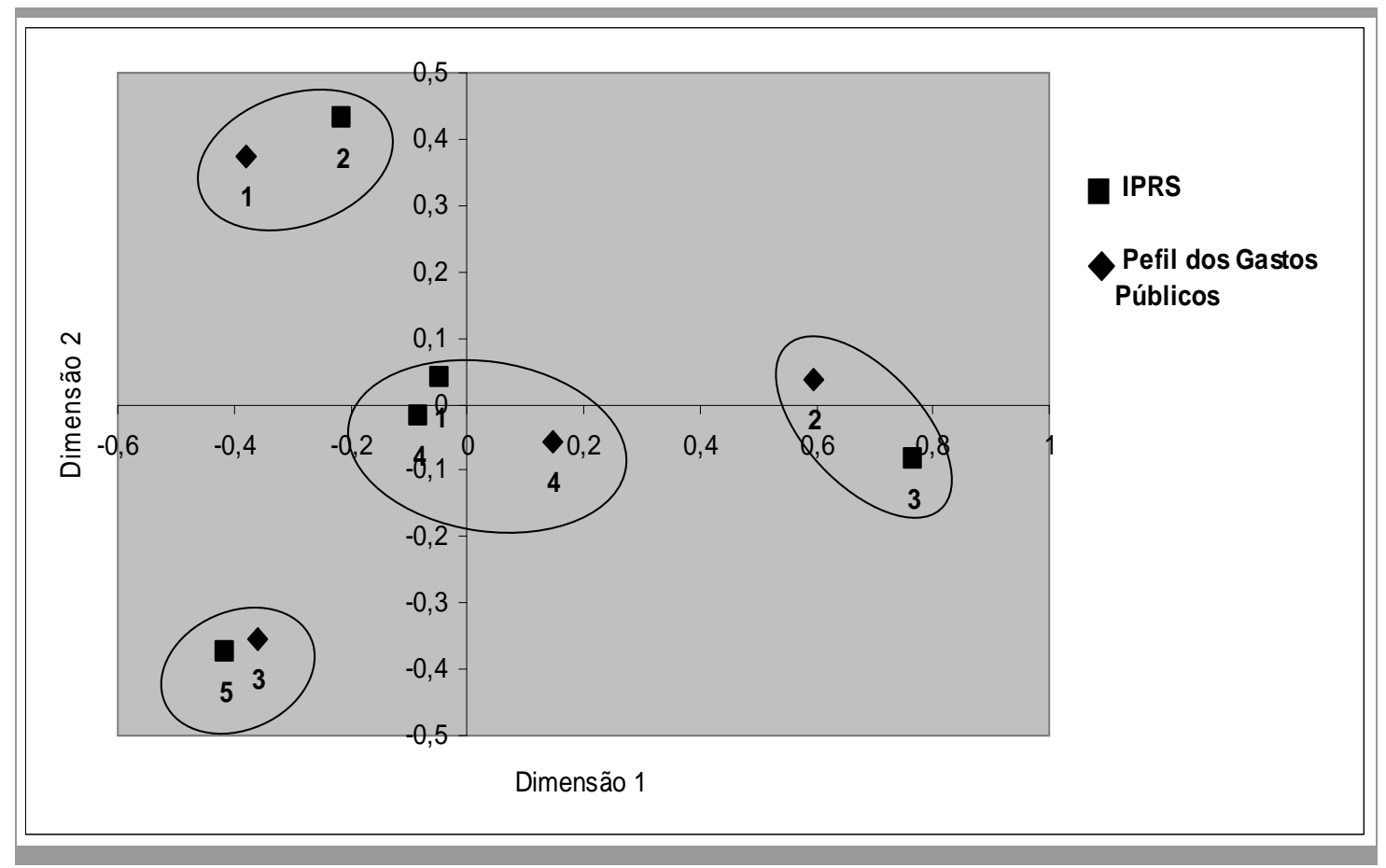

Figura 2 - Mapa Perceptual 
Os municípios caracterizados pelo IPRS por um nível elevado de riqueza e bons resultados quanto aos indicadores sociais (grupo 1) e por baixos indicadores de riqueza e níveis intermediários quanto aos indicadores sociais (grupo 4) associam-se ao conglomerado que realiza a segunda maior aplicação de recursos em praticamente todas as funções de governo, cuja prioridade dos gastos está na função Encargos Especiais e no Orçamento da Seguridade Social (Previdência, Assistência e Saúde).. No caso do grupo 1, por tratar-se de municípios-pólo, pode ser que exista um alto investimento com recursos privados, o que justificaria os bons indicadores sociais.

O grupo 2 do IPRS, municípios economicamente dinâmicos e de baixo desenvolvimento social, está próximo do conglomerado com os menores gastos em todas as funções de governo, exceto Encargos Especiais. Aparentemente, a riqueza municipal não se reverte em receitas públicas para financiar a prestação de serviços públicos e os encargos especiais podem representar um ponto de estrangulamento no desenvolvimento de políticas públicas.

O grupo 3 do IPRS, municípios saudáveis e de baixo desenvolvimento econômico, está próximo do conglomerado com maiores gastos per capita por função, mas que não possui uma boa qualidade do gasto público dado a relevância das aplicações nas funções Administração e Legislativa. Na área social, a prioridade dos gastos está nas funções Saúde e Educação e Cultura.

0 grupo 5 do IPRS, baixo desenvolvimento econômico e social, associa-se com o conglomerado que parece adotar as mesmas funções sociais como prioridade e apresenta gastos relevantes nas mesmas funções-meio, mas os valores aplicados foram intermediários. Contudo, este último grupo parece administrar melhor os gastos com encargos especiais.

A dimensão 1 é a que mais reteve informação. 0 conglomerado 2 quanto ao Perfil do Gasto Público e o grupo 3 do IPRS são as categorias que dominam tal dimensão, ou seja, estão mais afastadas da origem, indicando a relevância da análise de tais categorias. Os grupos 1 e 4 do IPRS e o grupo 4 quanto ao Perfil de Gastos Públicos estão muito próximos da origem, sendo pouco discriminativas.

\section{CONSIDERAÇÕES FINAIS}

0 presente artigo teve como objetivo realizar um agrupamento dos municípios paulistas, de acordo com seu perfil de gastos públicos per capita por função, e comparar os grupos obtidos com aqueles identificados pela Fundação SEADE com base nos indicadores de renda, longevidade e escolaridade.

0 interesse em fazer uma análise descritiva das relações entre perfil do gasto público por função e perfil econômico-social surgiu da constatação de grupos de municípios definidos pelo IPRS com mesmo nível de riqueza e indicadores de escolaridade e longevidade diferentes e vice-versa. Portanto, a premissa subjacente era que o montante e a qualidade dos gastos públicos estariam de alguma forma caracterizando tal situação.

As características dos bens públicos e a complexidade do seu processo produtivo dificultam estabelecer uma relação direta entre recursos orçamentários usados e os resultados alcançados pelos programas sociais. Todavia, a comparação dos municípios categorizados quanto ao perfil socioeconômico e de gastos públicos lança luz sobre os possíveis benefícios gerados à população pela reversão orçamentária em bens públicos. 
A análise de conglomerados sugeriu a formação de quatro conglomerados de municípios paulistas com base nas despesas liquidadas per capita por função. De diversas maneiras, todos os grupos de municípios apresentaram problemas de qualidade com a utilização dos recursos orçamentários.

O estudo das características dos agrupamentos pelos centróides indicou que o grupo com menor aplicação de recursos per capita (grupo 1), de certa forma, possui problemas quanto à qualidade do gasto público por não conseguir priorizar as funções sociais, além disso os gastos com Encargos Especiais são maiores do que em outros grupos.

0 grupo 2, com os maiores valores per capita de despesa, por sua vez, priorizou a função social Saúde, mas também as funções-meio Legislativa e Administração em detrimento de outras funções sociais como Educação e Cultura. 0 grupo 3 possui um perfil parecido, conseguindo priorizar as funções Educação e Cultura e Saúde, mas as também com altos gastos nas funções Legislativa e Administração.

0 grupo 4, por sua vez, não prioriza a função Educação e Cultura. Além disso, o desenvolvimento de políticas públicas parece ser dificultado pelos altos valores empregados nas funções Encargos Especiais e Assistência e Previdência.

As relações entre os grupos obtidos e aqueles formados pelo IPRS mostrou que o conglomerado de municípios com os maiores montantes de gasto, mesmo com problemas de qualidade, estava mais próximo daquele com maiores indicadores econômicos e sociais. Sendo estas duas categorias as mais relevantes na análise.

Apesar de associar-se ao conglomerado que indica má qualidade do gasto público por priorizar as funções Legislativa e Administração, o grupo 3 do IPRS consegue bons indicadores sociais, possivelmente pela maior disponibilidade de recursos públicos. 0 grupo 5 do IPRS está próximo de um perfil de gastos semelhante, mas com valores aplicados intermediários.

O grupo 2 do IPRS, apesar de economicamente dinâmico, possui baixo desempenho nos indicadores socioeconômicos, talvez pela menor disponibilidade de recursos públicos.

Os municípios-polo (grupo 1) e os de baixo desenvolvimento econômico e em transição social (grupo 5) apresentam associação com aqueles que tem níveis intermediários de gastos, com uma grande aplicação de recursos em Encargos Especiais e em Assistência e Previdência. Tais municípios não priorizam a função Saúde. No caso do grupo 1 , outros fatores podem contribuir para a sua boa performance econômico e social, como investimentos com recursos privados.

Sendo assim, é possível dizer que, em alguma medida, o montante e a qualidade dos gastos públicos relacionam-se com o perfil econômico e social dos municípios paulistas, confirmando a necessidade de avaliação dos gestores públicos não somente pelos indicadores econômico-sociais, mas agregando à análise dados sobre o orçamento público.

Sabe-se que o perfil econômico e social dos municípios paulistas não pode ser explicado exclusivamente pelos gastos públicos, outros fatores podem exercer influência, como gastos privados, localização, perfil da população, critérios de transferências de recursos por outros entes governamentais, capacidade tributária etc. Portanto, o estudo não é conclusivo, devendo ser aprofundado em relação a tais variáveis.

Não se pode afirmar que esse fato se repete entre os municípios dos outros estados do Brasil. Dessa forma, recomenda-se a repetição da análise em outras seleções de grupos de municípios. 


\section{REFERÊNCIAS}

AFONSO, A.; AUBYN, M. St. Non-parametric approaches to education and health expenditure efficiency in OECD countries. ISEG-UTL Economics Working Paper No. 1/2004/DE/CISEP/UECE. Febr. 2004.

AFONSO, A.; SCHUKNECHT, L.; TANZI, V. Public sector efficiency: an international comparison. ECB Working Paper Series No. 242. Jul. 2003.

ARROW, K. The organization of economic activity: issues pertinent to the choice of market versus non-market allocation. In: Joint Economic Committtee. The analysis and evaluation of public expenditures: The PPB system. Washington D.C.: U.S. GPO., 1970.

ARISTIGUETA, M. P.; COOKSY, L. J.; NELSON, C. W. The role of social indicators in the developing a managing for results system. Public Performance \& Management Review. v.24, n.3, p.254-269, March 2001.

BORGER, B.; KERSTENS, K. Cost efficiency of Belgian local governments: a comparative analysis of FDH, DEA and econometric approaches. Regional Science and Urban Economics. Amsterdam, v.26, n.2, p.145-170, 1996.

BORGER, B.; MOESEN, K.; KERSTENS, W.; VANNESTEK, J. Explaining differences in productive efficiency: An application to Belgian municipalities. Public Choice. Leiden, v.80, n.3-4, p.339-358, Sept. 1994.

BRADFORD, D. F.; MALT, R. A.; OATES, W. E. The rising cost of local public services: some evidence and reflections. National Tax Journal. Washington, v. 22, n. 2, p. 185-202, Jun. 1969.

BRASIL. Ministério do Planejamento, Orçamento e Gestão - MPOG. Portaria $n^{\circ} 42$, de 14/04/1999. Disponível em: <http://www.planejamento.gov.br/legislacao/conteudo/portarias.htm>. Acesso em 16 dez. 2003.

BURKHEAD, J. Orçamento público. Rio de Janeiro: Fundação Getúlio Vargas, 1971.

CAMPELLO, C. A. G. B. Eficiência municipal: um estudo no estado de São Paulo. São Paulo, 2003. Tese (Doutorado em Administração) - Programa de Pós-Graduação em Administração, Departamento de Administração, Faculdade de Economia, Administração e Contabilidade da Universidade de São Paulo.

COHEN, E.; FRANCO, R. Avaliação de projetos sociais. 6. ed. Petrópolis, RG: Vozes, 2004.

Fundação SEADE. Índice Paulista de Responsabilidade Social: consulta. Disponível em: <http://www.seade.gov.br/projetos/iprs>. Acesso em 24 abr. 2009.

Fundação SEADE. Índice Paulista de Responsabilidade Social: metodologia. Disponível em: <http://www.seade.gov.br/produtos/iprs/pdf/metodologia.pdf>. Acesso em 20 jan. 2005.

GIACOMONI, J. Orçamento público. 9. ed. São Paulo: Atlas, 2000.

GUPTA, S.; VERHOEVEN, M. The efficiency of government expenditure Experiences from África. Journal of Policy Modeling. New York, v.23, n.4, p.433-467, 2001.

HAIR JR., J. F.; ANDERSON, R. E.; TATHAM, R. L.; BLACK, W. C. Análise multivariada de dados. $5^{\mathrm{a}}$ ed. Porto Alegre: Bookman, 2005.

HOFFMAN, D. L.; FRANKE, G. R. Correspondence analysis: graphical representation of categorical data in marketing research. Journal of Marketing Research. Chicago: American Marketing Association, v. 23, n. 3, p. 213-227, ago. 1986. 
JANNUZZI, P. de M. Indicadores Sociais no Brasil: conceitos, fontes de dados e aplicações. São Paulo: Alínea, 2001.

MAROCO, J. Análise Estatística: com utilização do SPSS. 2. ed. Lisboa: Silabo, 2003.

MUSGRAVE, R. A.; MUSGRAVE, P. B. Finanças públicas: teoria e prática. São Paulo: Campus, 1980.

SAMUELSON, P. A. Diagrammatic exposition of theory of public expenditure. Review of Economics and Statistics. Massachusetts, v. 37, p. 350-356, 1955.

SAMUELSON, P. A. The pure theory of public expenditure. Review of Economics and Statistics. Massachusetts, v. 36, p. 387-389, 1954.

SCARPIN, J. E. Estudo dos fatores condicionantes do índice de desenvolvimento humano nos municípios do Estado do Paraná: instrumento de controladoria para a tomada de decisões na gestão governamental. São Paulo, 2006. Tese (Doutorado em Controladoria e Contabilidade) - Programa de Pós-Graduação em Ciências Contábeis, Departamento de Contabilidade e Atuária, Faculdade de Economia, Administração e Contabilidade da Universidade de São Paulo.

SHAH, A. A practitioner's guide to intergovernmental fiscal transfers. In: BOADWAY, R.; $\mathrm{SHAH}, \mathrm{A}$. Intergovernmental fiscal transfers: principles and practice. Washington, D.C.: World Bank, 2007.

SISTEMA DO TESOURO NACIONAL (STN). Estados e municípios. Disponível em: <http://www.stn.fazenda.gov.br/estados_municipios/index.asp> Acesso em 24 abr. 2009.

SOUSA, M. C. S.; CRIBARI NETO, F.; STOSIC, B. Explaining DEA technical efficiency scores in an outlier corrected environment: the case of public services in Brazilian municipalities. In: XXXI ENCONTRO NACIONAL DE ECONOMIA - ENANPEC, 2003, Porto Seguro. Anais do XXXI ENANPEC. Porto Seguro: ANPEC, 2003.

STIGLITZ, J. E. Public goods and publicly provided private goods. In: Economics of public sector. 2nd ed. New York: Norton, 1988.

TIEBOUT, C. M. A pure theory of local expenditure. Journal of Political Economy. Chicago, v. 64, n. 5, p. 416-424, 1956.

VARELA, P. S. Financiamento e controladoria dos municípios paulistas no setor saúde: uma avaliação de eficiência. São Paulo, 2008. Tese (Doutorado em Ciências Contábeis). Curso de Pós-Graduação em Ciências Contábeis, Faculdade de Economia, Administração e Contabilidade da Universidade de São Paulo.

VARIAN, H. R. Microeconomia: princípios básicos. Uma abordagem moderna. 7. ed. Rio de Janeiro: Campus, 2006.

\title{
ENDEREÇO DOS AUTORES
}

\author{
Universidade de São Paulo \\ Faculdade de Economia Administração e Contabilidade \\ Av. Luciano Gualberto, 908 - FEA 3 - sala 9 \\ Cidade Universitaria \\ Sao Paulo, SP - Brasil \\ 05508-900
}

